\title{
Ketamin/ksilazin anestezi hemoreolojik bakış açısından güvenlidir: bir ilk rapor "yazarın yanıtı-1"
}

\author{
Ilknur Hatice Akbudak, Ozgen Kilic Erkek, Egem Burcu Tuzcu, Hilmiye Pakyurek, Melek Bor
}

Kucukatay

Akbudak ve ark.'nın “Ketamin/ksilazin anestezi hemoreolojik bakış açısından güvenlidir: bir ilk rapor" başlıklı araştırma makalesi ile ilgili bir "Editöre Mektup" yazılarak çalışmayla ilgili bazı eleştirilerde bulunulmuş ve çalışmanın özgün olmadığı iddia edilmiştir. Bu yazı, iddialara cevap verilmesi ve çalışmanın "ÖZGÜN" olduğunun bilimsel kurallara uyularak, gerekli literatür bilgileri sunularak net biçimde ortaya konması amacıyla kaleme alınmıştır. “Editöre Mektup"taki iddialara aşağıda teker teker cevap verilecektir;

1.maddede değinilen tarihçe konusu ile ilgili olarak;

Makale ve mevcut tartışma ile direkt ilgisi olmamasına rağmen, hemoreoloji ve tarihçesi ile ilgili detaylı bilgiye "Handbook of Hemorheology and Hemodynamics" isimli kitabın incelenmesi ile ulaşılabilir [1]. Bu kitabın yazarları tüm dünyada "hemoreoloji" konusunda önde gelen araştırıcılar arasında sayılan bilim insanlarıdır. Bahsedilen kitabın ilgili bir bölümüne, yayında da 20 numara ile atıfta bulunulmuştur. Kitabın 1. bölümü hemoreolojinin tarihçesine ayrıımıştır [2]. Kitaptaki konuyla ilgili bilgilerin çok fazla oluşu buraya aktarılmalarını olanaksız kılmaktadır.

\section{2.maddede yer alan ifadelerle ilgili olarak;}

Refere edilen web sayfası incelenmiştir. $\mathrm{Bu}$ web sayfasının yazarlarının konuya ne kadar hakim olduğu, buradaki bilgilerin hakem gözetiminden geçip geçmediği belli değildir. Sayfada geçen "deformasyon" teriminin hemoreoloji alanında çalışan araştırıcılar tarafından kullanımınınönerilmemesi, yukarıdaki düşünceyi desteklemektedir. "Deformasyon" kelimesi istenmeyen bir değişimi ifade etmektedir. Oysa eritrosit deformabilitesi (şekil değiştirme yeteneği), özellikle mikrodolaşımdaki kan akımının devamlılığının sağlanması ve eritrositlerin fonksiyonlarını yerine getirmeleri için istenen, olması gereken, geri dönüşümlü bir fizyolojik mekanizmadır. Konu ile ilgili bazı bilimsel kaynak ve yaklaşımlar aşağıda özetlenecektir. Öte yandan, -bahsedilen kullanım hatasına rağmen-, kaynakta geçen "...özellikle de mikrodolaşımdaki kırmızı kan hücreleri deformasyonu ve kan viskozitesi ile ilişki temelinde "kan akımını inceleyen bilim" kısmı doğru olup, bizim makalemizde de tam olarak eritrosit deformabilitesi ve tam kan ile plazma viskozitesindeki değişimler farklı kayma hızlarında detaylı ve ileri teknik/cihazlarla incelenmekte ve bu anlamıyla özellikle de tam olarak "hemoreoloji" teriminin içine girmektedir.

Bilgi, makalemizde de giriş bölümü 3 . paragraf başında "Main components of hemorheology are flow, erythrocyte deformability and aggregation [11] whereas hematocrit (Hct) and plasma viscosity (PV) are determinants of whole blood viscosity (WBV). Capillary diameter is smaller than that of the red blood cell (RBC) in many parts of the circulation. For this reason, erythrocytes need to change their shape in order to maintain tissue oxygenation [12]." şeklinde referanslarıyla verilmiştir.

Ek olarak tartışmanın 3. paragrafında da, "Effectual blood supply plays an important role in proper maintenance of tissue metabolism and thus, function. Blood supply

Ilknur Hatice Akbudak, Ass. Prof. Pamukkale University Hospital, Department of Anesthesia and Reanimation, Kinikli, 20070 Denizli, Turkey, e-posta: ilhakbudak@gmail.com (https://orcid.org/0000-0001-9937-9169) (Corresponding Author)

Ozgen Kilic Erkek, PhD Student, Pamukkale University, Faculty of Medicine, Department of Physiology, Denizli, Turkey, e-posta: oerkek@pau. edu.tr (https://orcid.org/0000-0001-8037-099X)

Egem Burcu Tuzcu, Research Ass. Pamukkale University, Faculty of Medicine, Department of Physiology, Denizli, Turkey, e-posta: egemburcu. ebt@gmail.com (https://orcid.org/0000-0002-9499-2316)

Hilmiye Pakyurek, Research Ass. Pamukkale University, Faculty of Medicine, Department of Physiology, Denizli, Turkey, e-posta: hpakyurek@ pau.edu.tr (https://orcid.org/0000-0002-7084-3770)

Melek Bor Kucukatay, Prof. MD. Pamukkale University, Faculty of Medicine, Department of Physiology, Denizli, Turkey, e-posta: mbor@pau. edu.tr (https://orcid.org/0000-0002-9366-0205) 
and the metabolic tissues demand are kept in balance by vascular control mechanisms [32]. Much importance was not given to the hemorheological parameters as determinants of resistance to flow for many decades. On the other hand, vascular component has been studied extensively. Impaired hemorheological properties are known affect tissue perfusion negatively [33, 34]. The high deformability of the RBC facilitates blood flow even at high hematocrit, particularly in the microcirculation [35]. In addition, the ability of the entire RBC to deform is of crucial importance for performing its function in oxygen delivery. Deformability is also a determinant of the cell survival time in the circulation [11]. WBV is one of the components of the resistance to blood flow and perfusion of the microcirculation, although other factors such as pressure difference, sympathetic system activity, resistance of arterioles, local metabolic demand, local vasodilators such as nitric oxide and prostacyclin and other factors take place in the whole picture [36, 37]. The main determinants of WBV are PV, Hct, shear stress and shear rate, $R B C$ deformability, $R B C$ aggregation, fibrinogen concentration. and temperature [36]. This is why we measured WBV at otolog and standard Hct at different shear rates. Erythrocyte deformability is known as a major determinant at high shear stress whereas erythrocyte aggregation determines the WBV at low shear stress [38]." şeklinde bilgiler detaylandırılmıştır.

"Editöre Mektup"ta vurgulanmak istenen konunun şu şekilde olduğu anlaşılmaktadır; ketamin ve/veya ksilazinin "hemoreolojik parametre" olarak değerlendirilebilecek birtakım parametreler üzerindeki etkisi ile ilgili yayınlar mevcuttur (3. maddede bunların cevabı detaylı verilmiştir). Dolayısıyla mektubun yazarı makalenin girişinde geçen "Although some anesthetic drugs were demonstrated to cause microcirculatory disorders through cardiovascular and hemorheological effects [13-16], the influence of ketamine/xylazine anesthesia, on hemorheological parameters remains unknown. "cümlesinin doğru olmadığını iddia etmektedir.

Bu iddiaya şu cevaplar verilebilir;

i) Çalışmada yukarıda referanslarıyla verilen temel hemoreolojik parametreler incelenmiştir ve literatürde ketamin/ksilazin kombinasyonunun (90 $\mathrm{mg} / \mathrm{kg}-10 \quad \mathrm{mg} / \mathrm{kg}$ ) temel hemoreolojik parametreler olan eritrosit deformabilitesi, tam kan ve plazma viskozitesi üzerine etkilerini araştıran herhangi bir çalışma yoktur. Dolayısıyla makale özgündür. Nitekim makalenin giriş kısmında "Although some anesthetic drugs were demonstrated to cause microcirculatory disorders through cardiovascular and hemorheological effects [13-16], the influence of ketamine/xylazine anesthesia, on hemorheological parameters remains unknown. "Cümlesinden sonra aşağı satırlarda "Therefore, we aimed to investigate the effects of ketamine/xylazine $(90 \mathrm{mg} /$ $\mathrm{kg}$ ketamine-HCl/10 $\mathrm{mg} / \mathrm{kg}$ xylazine-HCl) anesthesia, on RBC deformability, WBV and PV in rats" cümlesi ile konu netleştirilerek literatürde eksik olan ve çalışma kapsamında incelenecek hemoreolojik parametreler detaylandırılmıştır. Metnin bu şekilde yazılmasının sebebi eritrosit deformabilitesi, tam kan ve plazma viskozitesi gibi parametrelerin tekrarından kaçınılmak istenmiş olmasıdır.

ii) Makale, dergi tarafından atanan hakemlerce okunmuş, incelenmiş, "Editöre Mektup"ta 4. maddede "Makalenin mevcut haliyle, okurların ketamin ve ksilazin gibi iki eski ilacın kan akımına etkileri ve bu bağlamdaki güvenilirlikleri konusunda daha önce hiçbir bilgi bulunmadığını sanmaları kaçınılmazdır." şeklinde ifade edildiği gibi bir yanlış anlama olmamıştır. Hakemler metni bütün olarak okuduklarında hangi hemoreolojik parametrelerin eksik olduğunu ve çalışma kapsamında bakılacağını, zaten "hemoreolojik parametre" terimi -zaman zaman geniş anlamda kullanılsa da- temel hemoreolojik parametrelerin hangileri olduğunu anlamışlardır. Bu çalışmada da ilgili parametrelerin bakıldığını tespit etmişler ki bu konuda hiçbir eleştiri yazmamışlardır. Okuyucuların da makaleyi bütünüyle okuyup anlamaya çalıştıklarında böyle bir -yanlış sanıiçinde olacaklarına ait objektif bir veri yoktur. Hakemli dergilere gönderilen makalelerde eksik, hatalı görülen, gözden kaçan, yeterince anlaşılmayan noktalar olabilir. Hakemler bunları belirtir ve gerekirse yazarlar düzeltir. Bizim makalemiz için de bu durum söz konusudur. Yazarların literatürde bakılmış olan hiçbir parametreyi bakılmamış gibi göstermek ya da çalışmayı orijinal olmadığı halde orijinal göstermek gibi bir kaygı içine düşmeleri söz konusu olamaz, çünkü zaten konu orijinaldir. 
Çalışma planlanmadan önce literatür taraması yapılmış, veriler elde edilip yazım aşamasına geçmeden önce yeni çıkan bir yayın olabileceği kaygısıyla tekrar tarama gerçekleştirilmiştir. Elde edilen literatür bilgilerinden konunun anlaşılması ve tartışılması amacıyla uygun görülenler makalede refere edilmiş, bu kaynaklar hakemlerce de uygun bulunmuştur. Makale yazımında uygulanması gereken bilimsel yol da budur. Makaledeki her cümle konuyu tam anlamıyla açıklayamaz; bu nedenle makalelerin tümünün dikkatlice okunması gerekir.

iii) Ek olarak yukarıda da belirtildiği gibi tartışma kısmında ".......Much importance was not given to the hemorheological parameters as determinants of resistance to flow for many decades. On the other hand, vascular component has been studied extensively. Impaired hemorheological properties are known to affect tissue perfusion negatively [33, 34]...." denerek konu açıklığa kavuşturulmuştur.

iv) Çalışmanın son yazarı yaklaşık 20 yıldır hemoreoloji konusunda çalışmalar yapmakta olup, bu konuda ileri düzey çalışmalar kabul eden uluslararası dergilerde yayınlar yapmış, konusunda bilgi ve tecrübe sahibi bir araştırıcıdır. Yazarın makalelerinde benzer cümle ve tanımlar kullanılmış, makaleler uluslararası hakemler tarafından incelenmiş, kabul edilmiştir. Okuyucular makaleleri okumuş, kendi yayınlarında refere etmişlerdir. Bugüne kadar hiçbir okuyucunun, "Editöre Mektup"ta madde 4'te belirtilen zanlara kapılması ile ilgili bir veri yoktur. Yazarın son 5 yılda basılan seçilmiş yayınlarından konuyla ilgili alıntılar aşağıdadır;

"Hemorheology and oxidative stress in patients with differentiated thyroid cancer following I-131 ablation/metastasis treatment." [3] isimli 2020 yılında yayınlanan çalışmada;

......"In this study, we aimed to investigate the effect of RAIT on haemorheological parameters, TOS/TASandOSlinpatientswithDTCs."şeklinde amaç cümlesi yazılmış, makalede hemoreolojik parametre olarak eritrosit deformabilitesi ve agregasyonu bakılmış, makale konunun uzmanı uluslararası hakemler tarafından incelenmiş ve yayınlanmıştır. Kimi zaman bazı araştırıcılar tarafından, fibrinojen, hematokrit vb. parametreler "hemoreolojik parametre" olarak ileri sürülmektedir. Ancak konu ile ilgili kapsamlı yayınlar incelendiğinde bu parametrelerin esas olarak eritrosit deformabilitesi, eritrosit agregasyonu, tam kan ve plazma viskozitesi gibi temel hemoreolojik parametrelerin anlaşılması amacıyla, bu parametrelerdeki değişikliklerin mekanizmalarının ortaya konması için tartışılııları görülecektir. Eritrositler, lökosit ve trombositlere göre sayıca çok fazla olduklarından kanın reolojik davranışının belirlenmesinde öncelikli rolü oynarlar [1]. Tam kan ve plazma viskozitesi yukarıdaki yayında çalışıımamıştır. Demek ki uluslararası kabule göre hemoreolojik parametre dendiğinde hepsinin çalışılması şart değildir. Hemoreolojik parametre ifadesi altında eritrosit deformabilitesi, tam kan ve plazma viskozitesi, eritrosit agregasyonu ve bunlarla ilgili literatür bilgilerinden bahsetmek yeterlidir. Yukarıdaki makalenin yayınlandığı Clinical Hemorheology and Microcirculation dergisi hemoreoloji alanında dünyadaki en kabul gören dergilerden biri olup hemoreoloji konusunda çalışan araştııııı tarafından yaygın olarak okunmaktadır. Makalenin başlığında bile "hemoreoloji" geçtiği halde konu ile ilgili hakemler makaleyi incelemiş, hemoreolojik parametre olarak eritrosit deformabilitesi ve agregasyonunun bakılmasını yeterli bulmuşlardır. Bizim yayında yapıldığı gibi, takip eden cümlelerde hangi hemoreolojik parametrelerin çalışıldığı açıklanabilir. Makale yayınlanmış ve hiçbir okuyucu madde 4'te belirtilen herhangi bir zanla geri dönüş yapmamıştır.

Konumuzdan bağımsız olarak, herhangi bir araştırma konusunun tüm parametrelerini tek bir çalışmada ölçmek hem teknik hem de araştırma bütçesi açısından imkânsız olacağı gibi, aynı zamanda da gereksizdir. Bir makalenin konu ile ilgili tüm sorulara cevap vermesi beklenmez.

"Hemorheological alterations following an acute bout of nordic hamstring exercise in active male participants 1" [4] isimli bir diğer çalışma da aynı dergide yayınlanmıştır

Yayında "Hemorheology is a branch of biorheology that deals with blood flow properties as well as the relationship between the vessel and the flowing blood [10]. The flow properties of blood play significant roles in tissue perfusion by contributing to hydrodynamic resistance in blood vessels. Erythrocyte deformability and red blood cell (RBC) aggregation are main components of hemorheology which are closely related with 
alterations in oxidative stress [11]. Additionally, exercise has been reported to induce significant alterations in blood rheology and oxidative stress [12-16] dependent on the type, duration, and intensity. The athletic capacity of the individual also plays a significant role [16]. However, alterations in blood rheology and oxidative stress parameters, following the eccentric 'Nordic hamstring exercise', remain unknown." denmektedir. Makalede eritrosit deformabilitesi, agregasyonu, hematokrit ve oksidatif stres incelenmiştir. Temel bir hemoreolojik parametre olan viskozite çalışılmamıştır. Buna rağmen abstractta "Hemorheological parameters were measured by an ektacytometer". denmekte ve başlıkta da "hemorheological alterations" ifadesi yer almaktadır. Tüm bu sayılanlara rağmen hiçbir hakem ya da okuyucu hemoreolojik parametre yazılmış ama sadece şunlar çalışılmış ya da sadece şu parametrelere ait literatür tartışımış gibi eleştiri/geri bildirimlerle dönüş yapmamıştır. Çünkü bahsedilen konu ile ilgili yeterli bilgiye sahip hakem ve okuyucular makalenin planlanması, çalışılması, yazılması sırasında doğru, uluslararası alanda kabul gören yaklaşımlar sergilendiğini anlamışlardır. Benzer durum mevcut makale için de geçerlidir.

"Impaired Blood Rheology in Pulmonary Arterial Hypertension." [5] isimli 2019 yılına ait yayında :

"In microcirculation, rheological characteristics of blood (i.e., erythrocyte deformability and aggregation, plasma viscosity) are the major determinants of resistance to flow and their alterations are known to impair microcirculatory blood flow [3-5]." denmektedir. $\mathrm{Bu}$ bilgi uluslararası hakemler tarafından okunmuş, doğru kabul edilip basılmasına onay verilmiştir. Yukarıdaki başlığa rağmen sadece eritrosit deformabilitesi ve agregasyonu çalışılmıştır. Hiçbir okuyucu hemoreolojik parametreler sadece bunları içermez diye bir geri dönüş yapmamıştır. Buradan çıkan sonuç; hemoreolojik parametre olarak eritrosit deformabilitesi, agregasyonu, tam kan ve plazma viskozitesinin uluslararası camiada yeterli ve geçerli kabul edildiğidir.

Uluslararası yayın örnekleri çoğaltılıp detaylandırılabilir; ancak konunun yeterince anlaşılmış olduğu düşünüldüğünden daha fazla örneklenmeyecektir. 3.maddede bir takım kaynaklar verilerek makalede neden refere edilmedikleri sorulmuştur. Bu referanslar aşağıda teker teker incelenecektir;

"Magora F, London M, Eimerl D, Aronson $H B$. Blood viscosity during anaesthesia with halothane, cyclopropane, thiopentone and ketamine. Br J Anaesth 1974;46:343-347. https://doi.org/10.1093/bja/46.5.343" künyeli yayının özet ve tam metnine çalışmanın planlanması ve yazımı aşamasında "pubmed" den ulaşılamamıştır. Bununla beraber, eğer çok gerekli olduğu düşünülse ulaşma yolları bulunabilirdi. Araştırıcılar, 1974 yılına ait çok eski bir yayının refere edilmesine gerek duymamışlardır. Akademik makalelerde refere edilebilecek yayın sayısı sınırlıdır ve bunların makaleye en fazla katkı sağlayacaklar arasından seçilmesi doğaldır. Makaleyi değerlendiren hakemler de benzer görüşte olmuşlardır ki, böyle bir talepte bulunmamışlardır. Kaldı ki yayında ketaminin kan viskozitesi üzerine etkisi incelenmiş olsa bile bizim çalışmamızda ketamin/ksilazin kombinasyonunun 0,3 ve 30 $\mathrm{Pa}$ arası 9 farklı kayma hızında lazer difraksiyon analiziyle eritrosit deformabilitesi, 38, 76 ve 190 $\mathrm{s}^{-1}$ kesme hızlarında standart (\%40) ve otolog hematokritte tam kan ve $190 \mathrm{~s}^{-1}$ kesme hızında plazma viskozitesine etkisi incelenmiştir. Sayılan sebeplerle, çalışmamızın orijinalitesini ortadan kaldıracak bir durumun söz konusu olmadığı açıktır. Detaylı eritrosit deformabilitesi ölçümleri yapan cihazlar bahsedilen yıldan oldukça sonrasına aittir. Ketamin ve ksilazin gibi iki molekülün ayrı ayrı etkilerinin, birlikte kullanıldıklarında ortaya çıkaracakları etkiden farklı olabileceği de açıktır.

Öte yandan, "Editöre Mektup" makalenin yazarlarına ulaştıktan sonra makalenin tam metnine ulaşılmıştır. Makalede minör cerrahi operasyon bekleyen 58 insanda halotan, siklopropan, tiopenton ve ketaminden (3 $\mathrm{mg} /$ kg'i.v $15 \mathrm{dk}$ sonra $1,5 \mathrm{mg} / \mathrm{kg}$ ) biri ile anestezi uygulanmıştır. Ek olarak, hastalara petidin ve/ veya atropin premedikasyonu uygulanmıştır. Ketamin uygulanan grupta kan viskozitesi ve fibrinojen konsantrasyonunun değişmediği, hematokritin arttığı tespit edilmiştir. Kan viskozitesi, literatür taraması sırasında yazarların hemoreoloji biliminin gelişimi doğrultusunda tahmin ettikleri gibi bizimkinden farklı 5 kayma hızında ve sadece standart 
hematokritte ölçülmüştür. Hematokrit kan viskozitesinin önemli bir belirleyicisi olduğundan günümüzde tam kan viskozitesi ölçümlerinin doğru yorumlanabilmesi için mutlaka otolog hematokrite ek olarak, düzeltilmiş standart hematokritte (\%40) de ölçülmesi gerektiği iyi bilinmektedir [6]. Bizim çalışmamızla 1974 yılına ait yayın arasındaki farklar altı çizili ve/veya koyu olarak verilmiştir. Farklar incelendiğinde bu makalenin varlığının, iddia edildiği gibi bizim çalışmamızın orijinalitesini bozmadığı açıktır.

"Lehmann Ch, Feyerherd F, Feyerherd
T. Ketamine does not affect intestinal
microcirculation in pentobarbital-anaesthetized
rats during experimental endotoxaemia
Lab Anim 2007;4:55-62. https://doi org/10.1258/002367707779399491" isimli makalenin özetine ulaşılmıştır. Literatür taramasında ilke, önce uygun anahtar kelimeler yazarak ilgili çalışmaların özetlerine ulaşmak, daha sonra özetlerin incelenmesiyle eğer makale direkt planlanan çalışmanın ilgi alanına giriyorsa tam metnine ulaşarak okumak, mevcut çalışmanın yapılandırılmasında kullanmak ve refere etmektir. Özetle, yukarıdaki kaynağın amacı, ketaminin deneysel endotoksemi sırasında pentobarbital ile anestezi uygulanan sıçanlarda bağırsak mikrosirkülasyonu üzerindeki etkilerini değerlendirmek olarak ifade edilmiştir. Tüm hayvanlara başlangıçta $60 \mathrm{mg} / \mathrm{kg}$ pentobarbital (i.p.) ile anestezi uygulandığı bildirilmiştir. Grup 1, kontrol olarak alınmıştır (18,5 mg/kg/saat pentobarbital i.v.). Grup 2 ve 4'e, Escherichia coli'den $15 \mathrm{mg} /$ $\mathrm{kg}$ lipopolisakarit (LPS) intravenöz endotoksin infüze edilmiştir. Grup 3 ve 4'e ayrıca 10 mg/kg/ saat ketamin (i.v.) uygulanmıştır. 2 saat sonra, intravital floresan mikroskobu (IVM) vasıtasıyla intestinal fonksiyonel kapiller yoğunluk (FCD) ve venüler endotelyuma lökosit yapışmasının incelendiği ifade edilmiştir. Sitokinler tümör nekroz faktörü (TNF) -alfa, interlökin (IL) -1beta, IL-6 ve IL-10'un salınımını belirlemek için kan örnekleri kullanılmıştır. Yazarlar, pentobarbital anestezisine ek olarak ketamin uygulamasının endotoksemi sırasında mikrosirkülasyonda değişikliklere veya sitokin salınımında değişikliklere neden olmadığı sonucuna varmışlardır. Sıçanlarda, pentobarbital ve ketamin kombinasyonunun, deneysel endotoksemide bağırsak mikrosirkülasyonu çalışması sırasında kullanım için uygun olduğunu ifade etmişlerdir. Yukarıdaki özetten

anlaşılacağı üzere bu makalenin ilgili yayında refere edilmesine hiç gerek yoktur.

Bunun sebepleri aşağıda özetlenmiştir;

i) Yayın pentobarbital anestezisine ek olarak ketaminin etkilerini ve üstelik tüm hemoreolojik parametreleri etkileyeceği çok iyi bilinen [7] endotoksemi modelinde incelemektedir. Bizim çalışmamızın konusu ketamin/ksilazin kombinasyonunun sağlıklı sıçanlarda etkilerinin incelenmesidir.

ii) Çalışmanın

bizim çalışmamızla

Bizim çalışmamızda kombinasyonunun sağlıklı sıçanlarda eritrosit deformabilitesi, tam kan ve plazma viskozitesi üzerine etkileri, bu kombinasyonun anestezi için kullanımının sıçanda ilgili parametrelerde herhangi bir değişikliğe sebep olup olmayacağı sorusunun cevaplanması amacıyla incelenmiştir.

Makale yazımında çalışma ile direkt ilgili makalelerin iyice araştırılarak, dikkatlice okunması ve uygun şekilde refere edilmesi gereklidir. Aksi taktirde bu kadar makalenin amacı, yöntemi, parametreleri, kullanılan deneysel yöntemlerle ilgisi olmayan yayınların refere edilmesi yolu seçilirse her bir makalenin okunamayacak ve değerlendirilemeyecek kadar uzun olacağı açıktır. Bu konunun tüm akademisyenler tarafından bilinmesi gerekir. Bu sebeple, birkaç anahtar kelime ile literatür taraması yapıp, yayınları yeterince incelemeden bunları neden refere etmediniz diye sormak etik bir yaklaşım değildir. Öte yandan, makalenin yayınlandığı dergi hakemli bir dergi olup, yazı hakemlerce incelenmiştir. Eğer bu yönde bir eleştiri gelseydi, hakemlere de gerekli cevaplar verilir, makale hakem önerileri doğrultusunda son haline getirilirdi. Bilimin geldiği noktada pek çok konuda çok sayıda yayına rastlanır. Konusunda deneyimli araştırıcıya düşen bunlardan kendi çalışması ile direkt ilgili olanları inceleyip, refere etmektir. Aksi takdirde hedefe odaklı bilimsel çalışmalar gerçekleştirilemez.

"Kanmura Y, Missiaen L, Casteels R. The effects of ketamine on $\mathrm{Ca} 2+$ movements in A7r5 vascular smooth muscle cells. Anesth Analg 1996;83:1105-1109. https://doi. org/10.1097/00000539-199611000-00036" isimli makalenin de özetine ulaşılmıştır. Bu çalışmada ketaminin hücre içi $\mathrm{Ca} 2$ + depolarına 
ve plazma membranlarından $\mathrm{Ca} 2+$ hareketi üzerindeki etkilerini araştırmak için, 45Ca2 + akıları (flux), embriyonik sıçan aortundan türetilen yerleşik bir hücre hattı olan geçirgen ve sağlam A7r5 düz kas hücrelerinde çalışılmıştır. Çalışma; amaç, kullanılan yöntemler, deneysel prosedür, incelenen parametreler ve varılan sonuçlar açısından bizim çalışmamızla hiçbir benzerlik göstermemektir. Tek ortak noktaları ikisinin de içinde "ketamin" geçmesidir. Kaldı ki bizim çalışmamızın amacı sadece ketaminin değil, laboratuvarımızda yaygın olarak kullanılan dozda intraperitoneal yolla uygulanan ketamin/ ksilazin kombinasyonunun (90 mg/kg-10 mg/ $\mathrm{kg}$ ) eritrosit deformabilitesi, tam kan ve plazma viskozitesi üzerine etkilerinin incelenmesidir. "Editöre Mektup"ta, ileri sürülen makaleyi refere edip nasıl bir bilimsel tartışma yürütülmesinin önerildiği gerçekten anlaşılamamıştır.

"Nakagawa $T$, Hirakata $H$, Sato M,
et al. Ketamine suppresses platelet
aggregation possibly by suppressed inositol
triphosphate formation and subsequent
suppression of cytosolic calcium increase.
Anesthesiology 2002:96:1147-1152. https://
doi.org/10.1097/00000542-20020500000018" isimli makalede ketaminin trombosit agregasyonunu baskıladığının bilindiğinden yola çıkılarak, bu etkinin mekanizmalarının araştırılması hedeflenmiştir. Ketaminin, muhtemelen IP3 oluşumunun ve ardından sitozolik serbest kalsiyum konsantrasyonunun baskılanmasıyla insan trombosit agregasyonunu inhibe ettiği sonucuna varılmıştır. Bu çalışmada yukarıda literatür bilgileri verilerek detaylı olarak açıklanan ve bizim çalışmamızda bakılan hemoreolojik parametrelerden hiçbiri incelenmemiş, ketamin/ksilazin kombinasyonu değil, sadece ketaminin trombosit agregasyonu üzerine etkisinin mekanizması değerlendirilmiştir. Bu yayının makalemizde refere edilmemesinin sebepleri yukarıdakiler ile benzer olup, daha fazla tekrara girmemek için açıklama bu şekilde sınırlandırılmıştır.

"Cross JP, Mackintosh CG, Griffin JF. Effect of physical restraint and xylazine sedation on haematological values in red deer (Cervus elaphus). Res Vet Sci 1988;45:281-286." isimli makaleden elde edilen bilgiler kapsamında, fiziksel kısıtlama veya ksilazin sedasyonu kullanılarak sağlıklı kızıl geyiklerden (Cervus elaphus) kan örnekleri alındığı anlaşılmıştır.
Fizikselkısıtlamanın bir geyik türü için çok ciddi bir stres sebebi olup, tek başına pek çok parametreyi bizim çalışmamızla karşılaştırılmasına gerek olmayacak şekilde etkileyeceği açıktır. Eritrosit, lökosit ve trombosit parametreleri, bir Technicon H6000 / C analizörü kullanılarak ölçülmüştür. Bu yöntemin bizim yöntemlerimizle ilgisi yoktur. Sakinleştirilmiş geyiklerde dolaşımdaki eritrosit kütlesi, lenfosit ve trombosit sayılarının azaldığı tespit edilmiştir. Ortalama eritrosit hacminin, muhtemelen dalaktaki genç eritrositlerin tercihli sekestrasyonu nedeniyle önemli ölçüde daha düşük olduğu yorumu yapılmıştır. Gözlemlenen farklılıkların ana nedeninin muhtemelen fiziksel kısıtlama sırasında dalak kasılması olsa da, düşük plazma viskozitesi ve fibrinojenin hemodinamik bir bileşeni de düşündürebileceği sonucuna varılmıştır. Bu çalışma denek türü ve bu türün özellikleri, kullanılan yöntemler, çalışılan parametreler, ulaşılan sonuçlar açısından makaleye öncelikli olarak katkı yapacak makaleler arasında görülmediğinden refere edilmemiştir. Hakemlerin de bu konuda bir uyarısı olmamıştır.

$\begin{array}{ccc}\text { "Raptopoulos D, Weaver } & \text { WM, } \\ \text { Papanastassopoulou } M, \quad \text { Staddon } & \text { GE, }\end{array}$
Parkinson TJ. The effect of xylazine on plasma thromboxane B2 concentration in sheep. J Vet Pharmacol Ther 1995;18:438-441. https://doi. org/10.1111/j.1365-2885.1995.tb00622.x" isimli makalede alfa 2-adrenoseptör agonisti ilaçların, koyunlarda kısa süreli hipoksemiye yol açan solunum değişikliklerine neden olabileceğinden bahsedilmiştir. Bunun geçici trombosit agregasyonu ve pulmoner mikroemboliden kaynaklandığı öne sürülmüştür. Çalışma, 0,1 $\mathrm{mg} / \mathrm{kg}$ 'ık bir dozda alfa 2-agonist ilaç ksilazinin intravenöz uygulamasından önce ve sonra plazma tromboksan B2 konsantrasyonlarını ölçmek için planlanmıştır. Plazma tromboksan konsantrasyonunun \%320 arttığı ve ayrıca artışın, bir alfa 2-adrenoseptör antagonisti olan atipamezol hidroklorürün $(0,125 \mathrm{mg} / \mathrm{kg})$ önceden uygulanmasıyla önlendiği bulunmuştur. Bu özeti okuyan akademik bilgi birikimine sahip kişilerin -yukarıdaki özetlerle benzer şekilde- ilgili makalenin neden çalışmada öncelikle refere edilmediğini anlamış oldukları düşünüldüğünden konu daha fazla uzatılmayacaktır.

Literatür taraması sırasında uygun anahtar kelimeler girilince çok sayıda makale çıkar. Bir makale kapsamında refere edilebilecek kaynak 
sayısı sınırlıdır. Makale yazılırken uygun şekilde sınırlanıp, okuyucuya esas verilmek istenen bilgilerin net ve öz olarak verilmesi, tartışılması gerekir. Bu amaçla bazı dergiler makalelerdeki kelime, sayfa, kaynak sayısını sınırlar, bu rakamların üzerindeki makaleleri kabul etmezler. Bizim makalemizde de zaten 40 referans kullanılmış olup, bu oldukça fazla bir sayıdır. Dolayısıyla, literatürden makale konusu ile direk ilgisi olmayan alıntıların yapılmaması doğaldır. Bu durumun yazının özgün değerini eleştirmek için kullanılması doğru değildir. Buna rağmen, yazarlar refere edilmesi önerilen makaleleri tek tek incelemiş ve refere etmeme sebeplerini sıralamışlardır. Yeterli akademik bilgi birikimine sahip ve konuya hakim kişiler bu satırları okuduğunda "Editöre Mektup"ta sıralanan makalelerin refere edilmeme sebeplerini net olarak anlayabileceklerdir.

\section{4. maddedeki eleştirilere istinaden;}

Yukarıda değinilen yayınlara makalenin tartışma bölümünde de neden değinilmediği akademik bilgi birikimine sahip kişilerce yeterince anlaşılabilecek şekilde detaylandırılmıştır. Makalenin mevcut haliyle, okurların ketamin ve ksilazinin çalışmamızın amacı olan hemoreolojik parametrelere etkileri ve bu bağlamdaki güvenilirlikleri konusunda doğru olmayan "sanı" lara kapılmalarının neden söz konusu olmayacağı da yukarıda literatür dayanakları verilerek detaylı olarak anlatıldığından tekrar edilmeyecektir.

Günümüz koşullarında, pek çok konuda bilgi birikimi vardır. Bilim insanlarından beklenen bunları okuyup, özümsemeleridir.

"Editöre Mektup" ta; "Sonuç olarak; bir çalışmanın özgünlük değerini saptamaya yönelik güvenilir bir literatür taraması yapabilmek için anahtar kelimelerin doğru belirlenmesi kritik önem taşımaktadır. Hedef yayınları atlamamak için tek bir terim ile yetinilmemesi, konu ile yakın ilgili ya da benzer anlamda kullanılabilen alternatif kelimelerin de özenle taramaya dahil edilmesi gerekir" denmektedir.

Çalışma ekibinde yer alan, çalışmanın planlanması, laboratuvar deneylerinin yapılması, yorumlanması ve makalenin yazılmasına katkılar sağlamış olan son yazarın özgeçmişi incelendiğinde "literatür taraması" yapılmasının ilkelerini bildiği açıktır. "Literatür taraması" yöntemleri ile ilgili önerilerde bulunmadan önce, konu ile ilgili yeterli sayıda bilimsel kaynak okunması gerekir. Bu bilimsel kaynakların özümsenmesi yıllar alır; süreç, emek ve ilgili konuda bilimsel tartışma ortamlarında bulunmayı gerektirir. Kişinin akademik değeri o güne kadar ortaya koyduğu bilimsel eserlerle ölçülür. Bilimsel çalışmalarına AKTiF olarak devam eden akademisyenler bunu iyi bilirler. Bilim insanlarının akademik etik değerlere uygun davranması önemlidir.

Sonuç olarak; gerekli bilimsel süreçler uygulanarak özgün bir çalışma planlanmış, laboratuvar analizleri yapılmış, yayına hazırlanmış, editör ve hakemler tarafından değerlendirilmiş ve basılmasının uygun olduğuna karar verilmiştir. Yazarlar, "Editöre Mektup" ta yöneltilen eleştirilerin hepsini cevaplamış ve doğru olmadıklarını literatürden kaynaklar göstererek ortaya koymuşlardır. Makalenin bilime katkı sağlaması, yeni çalışmalara öncülük etmesi umulmaktadır.

Çıkar ilişkisi: Yazarların herhangi bir çıkar ilişkisi yoktur.

\section{Kaynaklar}

1. Baskurt OK, Hardeman MR, Rampling MW, Meiselman HJ. (eds), Handbook of Hemorheology and Hemodynamics. IOS Press: Netherlands, 2007

2. Rampling MW. History of Hemorheology, In: Handbook of Hemorheology and Hemodynamics, Baskurt OK, Hardeman MR, Rampling MW, Meiselman HJ. (eds), IOS Press: Netherlands, 2007

3. Sengoz, T, Kilic Toprak E, Yaylali O, et al. Hemorheology and oxidative stress in patients with differentiated thyroid cancer following I-131 ablation/metastasis treatment. Clin Hemorheol Microcirc 2020;74:209-221. https://doi.org/10.3233/CH-190717

4. Unver F, Kilic Toprak E, Kilic Erkek O, et al. Hemorheological alterations following an acute bout of nordic hamstring exercise in active male participants. Clin Hemorheol Microcirc 2019;71:463-473. https://doi. org $/ 10.3233 / \mathrm{CH}-180402$

5. Yaylali YT, Kilic Toprak E, Ozdemir Y, Senol H, Bor Kucukatay M. Impaired Blood Rheology in Pulmonary Arterial Hypertension. Heart Lung Circ 2019;28:10671073. https://doi.org/10.1016/j.hlc.2018.07.014

6. Lowe GDO, Barbenel JC. Plasma and blood viscosity. In: Lowe GDO (eds.), Clinical Blood Rheology Boca Raton: FL CRC Press, 1988;1:11-44.

7. Myung J, Park SJ, Lim J, Kim YH, Shin S, Lim CH. Effects of lipopolysaccharide on changes in red blood cells in a mice endotoxemia model. Clin Hemorheol Microcirc 2016;63:305-312. https://doi.org/10.3233/ $\mathrm{CH}-152017$ 
Ketamin/ksilazin anestezi hemoreolojik bakış açısından güvenlidir: bir ilk rapor "yazarın yanıtı-2"

Ilknur Hatice Akbudak, Ozgen Kilic Erkek, Egem Burcu Tuzcu, Hilmiye Pakyurek, Melek Bor Kucukatay

"Editöre Mektup" un yazarı tarafından sonradan eklenen istatistik ile ilgili nota cevap olarak;

Çalışmanın başında 11 sıçana ait ilk sonuçlar bildiri olarak yayınlanmıştır. Bildiride, İstatistik Anabilim dalı ile de görüşülerek SD'u çok bozan/ etkileyen bir değer çıkarılarak $n=11$ üzerinden bildiri yapılmıştır.

Yayın için sonradan eklenen hayvanlardan elde edilen değerlerin ilk inceleme yapılan 11 hayvandan elde edilenlerden yüksek olmasından dolayı SD beklenenden daha yüksek çıkmıştır. Yayında " $n$ " sayısı arttığı zaman $(n=17)$ yeniden İstatistik Anabilim Dalı ile görüşülerek "n" sayısında SD'u etkileyecek anormal bir artış olmadığı düşünülmüş ve bazı sonuçlardaki değerler nedeniyle böyle bir fark oluştuğu kanaatine varılmıştır. 